\title{
Percepção e uso de mata ciliar em um projeto de assentamento, Santarém (PA)
}

As matas ciliares são áreas de preservação ambiental, protegidas pela legislação florestal brasileira, dada sua função de proteção do solo e recursos hídricos. 0 objetivo deste trabalho foi avaliar a percepção dos comunitários e o uso da mata ciliar na comunidade de Santa Luzia, Projeto de Assentamento Agroextrativista do Eixo forte, Santarém (PA). Esta pesquisa foi realizada ao longo do primeiro semestre do ano de 2014. Para a realização do trabalho, primeiramente foi realizada uma visita para o conhecimento da área e contato com as lideranças comunitárias, visando obter autorização para realização do estudo. Como instrumento de coleta de dados, adotou-se o uso de entrevista semiestruturada, anotações dos comentários dos entrevistados, observação direta e registro fotográfico. O estudo realizado na comunidade de Santa Luzia mostrou que os comunitários possuem conhecimentos sobre os recursos naturais existentes na comunidade, com destaque o igarapé e a composição da mata ciliar. Há a sensibilização dos visitantes, principalmente os que têm balneários, para as questões ambientais. No entanto, ainda ocorrem descartes irregulares de resíduos às margens do igarapé da comunidade. O conhecimento sobre a legislação ambiental envolvendo a mata ciliar é superficial, havendo ainda muitas limitações. Assim, surge a necessidade de ampliar as ações extensionistas voltadas para as questões de legislação ambiental.

\section{Perception and use of riparian forest in a settlement project, Santarém (PA)}

\begin{abstract}
Riparian forests are areas of environmental preservation, protected by Brazilian forest legislation, given their function of soil protection and water resources. The objective of this work was to evaluate the perception of the community and the use of riparian forest in the community of Santa Luzia, Agroextrativista Settlement Project of the Strong Axis, Santarém (PA). This research was conducted during the first semester of 2014. To carry out the work, a visit was first made to the knowledge of the area and contact with community leaders, seeking authorization to conduct the study. As a data collection instrument, the use of semi-structured interviews, notes of the interviewees' comments, direct observation and photographic record were adopted. The study conducted in the community of Santa Luzia showed that community members have knowledge about the natural resources in the community, especially the stream and the composition of riparian forest. There is an awareness of visitors, especially those who have changing rooms, about environmental issues. However, irregular waste disposal still occurs on the margins of the community stream. Knowledge about environmental legislation involving riparian forest is superficial, with many limitations. Thus, the need arises to expand extension actions focused on environmental legislation issues.
\end{abstract}

Keywords: Environmental perception; Areas of Permanent Preservation; Environment; Amazon.

Topic: Uso de Recursos Naturais

Reviewed anonymously in the process of blind peer.
Received: 23/08/2018

Approved: 28/08/2018
Alessandra dos Santos Gomes (iD)

Instituto Esperança de Ensino Superior, Brasil

http://lattes.cnpq.br/9223674217531996

http://orcid.org/0000-0001-5377-5633

ale engenhariaflorestal@yahoo.com.br

\section{Thiago Almeida Vieira (D)}

Universidade Federal do Oeste do Pará, Brasil

http://lattes.cnpq.br/4121093782754551

http://orcid.org/0000-0001-9926-2606

thiago.vieira@ufopa.edu.br
Referencing this:

GOMES, A. S.; VIEIRA, T. A.. Percepção e uso de mata ciliar em um projeto de assentamento, Santarém (PA). Revista Ibero-Americana de Ciências Ambientais, v.9, n.6, p.307-320, 2018. DOI: http://doi.org/10.6008/CBPC2179-6858.2018.006.0029 


\section{INTRODUÇÃO}

Atualmente, vem se observado um aumento na ocupação territorial, com aumento de demanda por supressão da vegetação. Estas e outras alterações ambientais levam muitas vezes a danos ambientais severos, demonstrando a necessidade de se estudar, analisar e propor métodos de recuperação ambiental conforme padrões estabelecidos pela legislação brasileira.

Mesmo as pessoas dependendo do meio ambiente, ainda se precisa aumentar práticas de sensibilização ambiental, por isso, é necessária a criação e execução de políticas que visem o melhor uso dos recursos naturais, uma vez que todos tem o direito de usufruir de um meio ambiente ecologicamente equilibrado. Oliveira et al. (2011) comenta que

As civilizações surgiram ao redor dos rios e lagos e essa ocupação ocorreu devido a necessidade de residirem em locais onde lhes fosse garantida a sua sobrevivência [...]. Assim, muitas cidades surgiram e se desenvolveram no entorno de bacias hidrográficas e, desta forma, os recursos hídricos acabaram por sofrer contaminação, poluição e descaracterização de grande parte dos rios e lagos existentes.

De acordo com Moro et al. (2005), as matas ciliares se constituem em um tipo de formação vegetal mais importante para a preservação do equilíbrio da natureza, uma vez que protegem rios, córregos e mananciais, retendo as impurezas e preservando a qualidade da água. Contudo, dada sua importância nos diversos setores de atividades do uso do solo, estas matas têm sofrido com as mais variadas formas de exploração.

A partir da percepção do indivíduo, podem-se buscar mecanismos para sensibilizá-lo para a importância da conservação e preservação das matas ciliares, haja vista que estas são fundamentais para o equilíbrio ambiental. No entanto, em algumas situações considera-se que a mata ciliar é apenas o estrato arbóreo, deixando a vegetação rasteira de lado, não sendo esta menos importante, devendo, portanto, ser mantida.

Tem-se questionado de maneira muito veemente como está sendo feita a utilização dos recursos naturais. Tanto no meio científico, quanto na sociedade, é crescente a ideia de conservação e recuperação dos ecossistemas onde vive o homem, os quais vêm sendo modificado de maneira negativa, causando inúmeros prejuízos ao meio (REVELINI, 2011). Segundo Cunha et al. (2009), a questão ambiental se torna cada vez mais emergente, as várias atitudes já adotadas com o intuito de frear a crescente degeneração do planeta não foram suficientes, aproximando nossa sociedade do iminente caos ambiental.

Para reverter essa situação, é necessário sensibilizar os seres humanos para as questões ambientais, despertando em cada indivíduo a percepção ambiental. Para Nascimento et al. (2011), a partir da avaliação do nível de percepção ambiental de um grupo de pessoas é possível compreender a opinião dos mesmos diante das mazelas ambientais às quais estão sujeitos, e colocar em prática trabalhos de educação ambiental que sejam pertinentes à realidade observada, garantindo-se, assim, o sucesso dos mesmos.

Diante disso, o presente estudo teve por objetivo avaliar a percepção dos comunitários e o uso da mata ciliar na comunidade de Santa Luzia, Projeto de Assentamento Agroextrativista do Eixo forte, Santarém (PA). Para isso, diagnosticou-se a percepção dos comunitários em relação a importância da mata ciliar e seu uso na comunidade de Santa Luzia. 


\section{REVISÃO TEÓRICA}

\section{Meio Ambiente}

No âmbito legal, de acordo com o artigo 3ำ, inciso I, da Lei Federal no 6.938/1981, que dispõe sobre a Política Nacional do Meio Ambiente, tem-se que 'meio ambiente, o conjunto de condições, leis, influências e interações de ordem física, química e biológica, que permite, abriga e rege a vida em todas as suas formas'. Entretanto, meio ambiente não se resume a recursos naturais, tampouco ao que está ao redor do homem, pois este é parte desse meio, integrando-o e interagindo com ele. O homem faz parte do meio ambiente, devendo, portanto, cuidar, preservar e mantê-lo para que as futuras gerações também possam usufruir de forma sustentável (SCARDUA, 2009). Para Sánchez (2006),

O conceito de "ambiente", no campo do planejamento e gestão ambiental, é amplo, multifacetado e maleável. Amplo porque pode incluir tanto a natureza como a sociedade. Multifacetado porque pode ser aprendido sob diferentes perspectivas. Maleável porque, ao ser amplo e multifacetado, pode ser reduzido ou ampliado de acordo com necessidades do analista ou interesses dos envolvidos.

O meio ambiente compreende, de uma forma bastante genérica, o quadro climático e físico-químico no qual a população evolui, as fontes alimentícias (espécies presas, elementos minerais ou matéria orgânica morta segundo o caso) e inúmeras outras populações, que podem interagir com a espécie estudada, seja negativamente (competidores que com ela concorrem na exploração da alimentação ou na ocupação do espaço), seja positivamente (mutuários ou simbiontes que com ela cooperam na garantia ou no aperfeiçoamento de tal ou tal função). Devemos englobar aqui todas as espécies cuja ação sobre o meio ambiente o modifica, num sentido favorável ou desfavorável à população analisada. Dessa maneira, para cada indivíduo da população estudada, seus congêneres também constituem um componente do meio ambiente em que os efeitos devem ser considerados (BARBAULT, 2011).

\section{Percepção Ambiental}

"A percepção é um fator presente em toda a atividade humana, tendo efeito marcante no envolvimento deste com as paisagens, influenciando diretamente na conduta frente às mesmas" (SOARES, 2007). O ser humano, ao longo de sua evolução histórica, tem se apegado menos aos sistemas naturais e sociais. Encantado pelo avanço tecnológico esqueceu que é parte integrante destes sistemas. Usa os recursos ambientais como se fossem inesgotáveis e sempre disponíveis. Em decorrência disso, convive-se com vários problemas, os quais concorrem para a crise ambiental e refletem a falência dos modelos que regem a sociedade contemporânea (SILVA et al., 2008).

O estudo da percepção não é tarefa de um único campo do conhecimento. Teorias diferentes sobre percepção são encontradas em várias áreas com diferentes enfoques. As sensações é que indicam as qualidades, as impressões dos objetos e consequentemente os significados e valores atribuídos por cada indivíduo (MELAZO, 2005). "Percepção ambiental abrange a maneira de olhar o ambiente. Consiste na forma como o ser humano compreende as leis que o regem. Esse ver ocorre através de uma imagem resultante de conhecimentos, experiências, crenças, emoções, cultura e ações" (SILVA et al., 2008). 
Para Oliveira et al. (2009), "a percepção ambiental acaba então por estabelecer os vínculos afetivos do indivíduo com o ambiente vivido por meio das imagens percebidas e seus significados, as sensações, as impressões e os laços afetivos ali construídos". Terrassumi (2008) comenta que a percepção ambiental tem sido estudada em diversas áreas do conhecimento como, por exemplo, a psicologia, a biologia, e a antropologia, e tem como objetivo compreender os fatores, mecanismos e processos que levam as pessoas a terem determinadas atitudes e opiniões no que se refere ao meio a qual estão inseridas. As pesquisas relacionadas à percepção ambiental investigam os valores, necessidades, julgamentos, atitudes e expectativas que determinados grupos têm em relação a uma dada paisagem por eles de alguma forma vividas. Oliveira et al. (2008) comenta que

O estudo sobre a percepção ambiental, neste sentido, é um meio de compreender como os sujeitos de diferentes sociedades adquirem seus conceitos e valores, bem como, como compreendem suas ações e se sensibilizam com a crise socioambiental. A Educação ambiental tendo conhecimento dos valores e ações que os sujeitos possuem frente ao meio ambiente será capaz de elaborar propostas que venham a atingir grande parte da sociedade, visando provocar mudanças mais efetiva que contribuam para a sustentabilidade socioambiental.

Para Melazo (2005), o estudo da percepção ambiental torna-se fundamental para entender as interrelações entre o homem e o ambiente, suas expectativas, satisfações e insatisfações, valores e condutas, como cada indivíduo percebe, reage e responde de maneira diferente diante às ações sobre o meio. $O$ estudo deve buscar não apenas o entendimento do que o indivíduo percebe, mas também promover a sensibilização, a consciência, bem como o desenvolvimento só sistema de compreensão do ambiente ao seu redor.

\section{Matas ciliares}

As matas ciliares são um dos tipos de Áreas de Preservação Permanente (APPs), consideradas importantíssimas por protegerem nascentes, e minimizarem o impacto da erosão em áreas mais altas, em que podem influenciar de forma negativa na qualidade e quantidade das águas superficiais (GALAVOTTI, 2005). De acordo com Attanasio et al. (2006), as matas ciliares atuam na contenção de enxurradas, na infiltração do escoamento superficial, na absorção do excesso de nutrientes, na retenção de sedimentos e agrotóxicos, colaboram na proteção da rede de drenagem e ajudam a reduzir o assoreamento da calha do rio, além de favorecer o aumento da capacidade de vazão durante a seca.

Para Fendel (2007), estas matas são essenciais para o equilíbrio do meio ambiente. Sua preservação ou recuperação beneficia uma grande quantidade de animais que se alimentam de frutos e folhas ali existentes, como também a biota aquática e os microrganismos do solo, que se beneficiam do material orgânico resultante da vegetação ciliar. Além disto, a mata ciliar tem como função a proteção das águas e do solo, evitando a erosão e o assoreamento dos rios. Portanto, também o ser humano aproveita de melhor qualidade hídrica.

Para o meio rural, as APPs assumem importância fundamental para quem almeja o desenvolvimento sustentável. Tomando como exemplos as APP mais comumente encontradas no ambiente rural, como áreas de encostas acentuadas, as matas ciliares em áreas marginais de córregos, rios e reservatórios, bem como 
áreas próximas às nascentes, é possível apontar uma série de benefícios ambientais decorrentes da manutenção dessas áreas dessa forma, destaca-se os serviços ecológicos das APPs que são: fixação de carbono, refúgio e alimento para a fauna terrestre e aquática, fornecimento de refúgio e alimento (pólen e néctar) para os insetos polinizadores de culturas entre outros (SKORUPA, 2003).

\section{METODOLOGIA}

\section{Área de estudo}

A comunidade de Santa Luzia existe há aproximadamente 70 anos. Até 1992 ela era conhecida como 'Ramal Caruara', em função da ocorrência de muitas árvores chamadas caruareiras. O ramal Caruara pertencia à comunidade de São Braz, a três quilômetros de distância desta, o que dificultava a participação dos moradores do ramal nas atividades da comunidade. Então as famílias do ramal fundaram nesse ano um grupo de oração dominical domiciliar. Em 30 de maio de 1992, devido à necessidade da prática do esporte como meio de lazer e diversão e, por participarem de times de outras comunidades, os moradores fundaram o time de futebol de representasse a nova comunidade, chamado Grêmio Recreativo Caruarense - GRC.

Em 25 de dezembro de 1992 já era considerada como uma comunidade, todos os domingos aconteciam encontros de oração dominical, sendo que cada encontro ocorria em uma residência diferente. Já no âmbito do clube de futebol, os mais experientes começaram a pensar em transformar o ramal em comunidade católica independente e, a partir desta data, começou a vigorar a existência da mesma, no entanto, sem nome, ou seja, apenas pelo antigo nome, Caruara.

$\mathrm{Na}$ data de 10 de janeiro de 1993, ocorreu a votação para escolher o nome, ficando entre o do padroeiro São Tomé e Santa Luzia e ao final da votação foi escolhido o nome de Santa Luzia para ser padroeira da nova comunidade. 0 estudo foi desenvolvido na comunidade Santa Luzia com aproximadamente 21 famílias constante na Relação de Beneficiários (lista com famílias beneficiárias) do Instituto Nacional de Colonização Reforma Agrária no ano de 2014. A comunidade está localizada no Projeto Agroextrativista (PAE) Eixo Forte, com ramal de acesso pela Rodovia Everaldo Martins (PA-457), na altura do Km 15, município de Santarém, oeste do estado do Pará (figura 1).

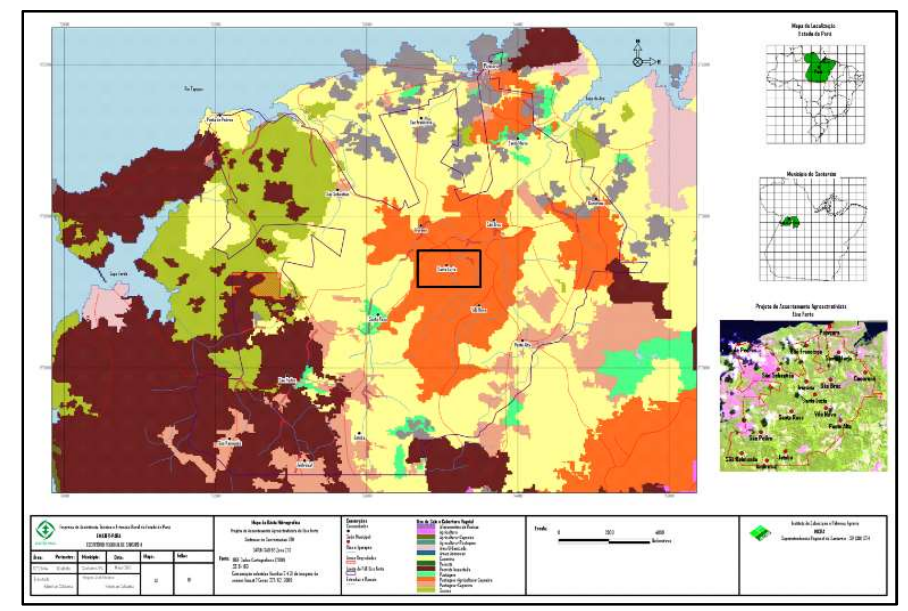

Figura 1: Localização da área de estudo. 
De acordo com a classificação de Köppen, o clima é do tipo Ami (quente e úmido). No que se refere aos aspectos climáticos, suas precipitações anuais variam entre 1900 a 2100mm, com frequência de dias com ocorrência de chuva ao longo do ano em torno de 126 a 150 dias. A temperatura do ar, considerando a média compensada, ou seja, a média entre a temperatura máxima e mínima, chega a $26^{\circ} \mathrm{C}$. A umidade relativa média anual é elevada, com valores em torno de 84,1 a 86\% (UCHOÂ, 2011).

A comunidade tem como característica a ocorrência de açaizal (povoamento de Euterpe oleracea Mart., conhecido por Açaí) ao longo dos igarapés que cortam a comunidade (figura 2). Devido a expressiva quantidade desta palmeira, o açaí tornou-se a principal fonte agrícola de renda das famílias que utilizam recursos naturais como forma de geração de renda.

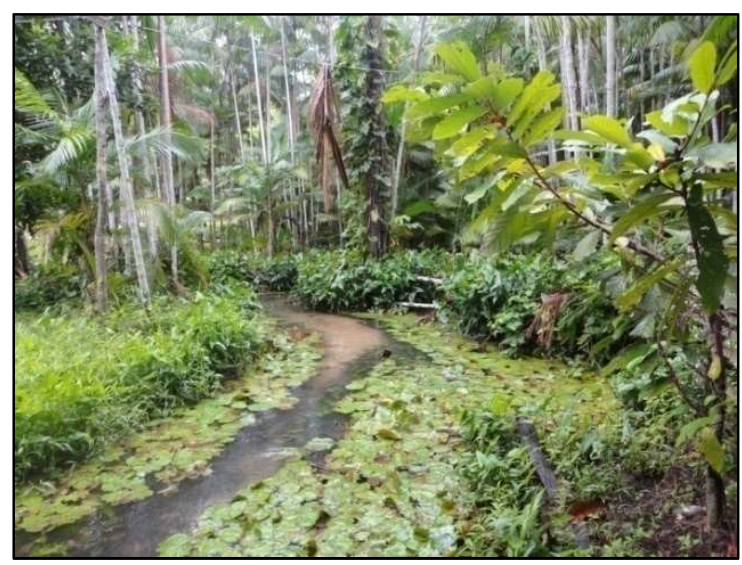

Figura 2: Aspecto do igarapé e mata ciliar com indivíduos de Euterpe oleracea, comunidade de Santa Luzia, Santarém (PA).

\section{Coleta dos Dados}

Para a realização do trabalho primeiramente foi realizada uma visita para o reconhecimento da área e contato com as lideranças comunitárias, visando obter autorização para realização do estudo. Como instrumento de coleta de dados, adotou-se o uso de entrevista semiestruturada. A amostra foi do tipo não probabilística intencional, de modo que foram entrevistadas 21 famílias, sem diferenciação de gênero, origem ou geração e dispostas a participar do estudo. Algumas das pessoas estavam presentes na relação de beneficiário do Incra da comunidade, isto é, eram beneficiárias das políticas de reforma agrária, sendo assentadas neste projeto de assentamento agroextrativista. Esta aplicação foi precedida da apresentação e assinatura do Termo de Consentimento Livre e Esclarecido - TCLE para cada assentado entrevistado.

As entrevistas foram realizadas nas residências deles, a fim de que fossem realizadas observações diretas sobre existência da mata ciliar no entorno. Paralelamente foram anotados comentários dos entrevistados no decorrer das entrevistas, o que colaborou nas interpretações de alguns dados. No ato das visitas realizou-se também o registro fotográfico das áreas apontadas pelos entrevistados como mata ciliar. Estas imagens ajudariam a verificar de forma preliminar a ocorrência de impactos ambientais, os quais serão considerados os seguintes: solo exposto, resíduos depositados no curso d'água ou na margem, benfeitorias, banheiro, vestígios de queimada, presença de poço, barreiras de contenção e cerca e assoreamento no curso d'água. 


\section{Análise da percepção dos comunitários}

Concluída a etapa das entrevistas, foi realizada a construção dos perfis dos entrevistados e da propriedade, além da percepção ambiental da comunidade, sob a ótica do entrevistado. Os impactos ambientais observados foram classificados conforme a percepção do assentado em uma escala que variou de baixo, médio a alto. Para triangular esta percepção, adotou-se a observação direta, e o registro fotográfico como técnicas de confirmação. Para a análise dos dados usou-se o programa Microsoft Excel for Windows ${ }^{\circ}$, por meio da confecção de gráficos e tabelas, analisados pela estatística descritiva. Algumas respostas dos entrevistados foram inseridas nos resultados, mantido ao sigilo da identidade, para exemplificar as percepções.

\section{RESULTADOS}

\section{Perfil dos entrevistados}

Na comunidade de Santa Luzia, os entrevistados em sua maioria são mulheres (66,7\%). A idade dos entrevistados variou de 19 anos a 85 anos. Observou-se que a maioria tem até 59 anos (80,9\%), e somente 19\% com mais de 60 anos. Com relação ao tempo de residência do entrevistado na comunidade, 71,4\% residem de uma a 10 anos e $28,6 \%$ a mais de 10 anos. Destaca-se que $57,1 \%$ dos entrevistados não nasceram na comunidade. Com relação ao nível de escolaridade, foi constatado que $42,9 \%$ dos entrevistados concluíram o Ensino médio, 9,5\% tem o Ensino médio incompleto, 4,8\% Ensino fundamental completo, 28,5\% o Ensino fundamental incompleto, 4,8\% Superior incompleto e 9,5\% possui Pós-graduação.

\section{Perfil das propriedades}

Os tamanhos das áreas dos lotes/propriedades dos entrevistados variaram de 0,033 a 89ha, onde $85,7 \%$ representam propriedades com até 10 ha, $9,5 \%$ até 20 ha e $4,8 \%$ com mais de 20 ha, denotando um processo de minifundiarização na comunidade. Com relação a processos produtivos, constatou-se que 95,2\% desenvolvem alguma atividade produtiva na propriedade, com destaque para o manejo do açaí, extração das polpas de cupuaçu (Theobroma grandiflorum) e taperebá (Spondias sp.), espécies com maiores valores de produtividade e comercialização, segundo os entrevistados. O açaí se destaca economicamente, atribuindose a isto a ocorrência do Festival do Açaí, o qual movimenta a comunidade na primeira semana do mês de novembro de cada ano.

As outras atividades produtivas mencionadas foram: criação de galinha caipira, de carneiro, cultivo agrícola (milho, mandioca, macaxeira, abacaxi, batata doce e cará). Somente 4,8\% não exercem atividade produtiva ligada à agricultura. Quanto à existência de benfeitorias nas propriedades, conforme a figura 3, foi constatado que $52,4 \%$ possuem poço; galinheiro (47,6\%); casa de beneficiamento de açaí (14,3\%); banheiro fora da casa $(14,3 \%)$. 


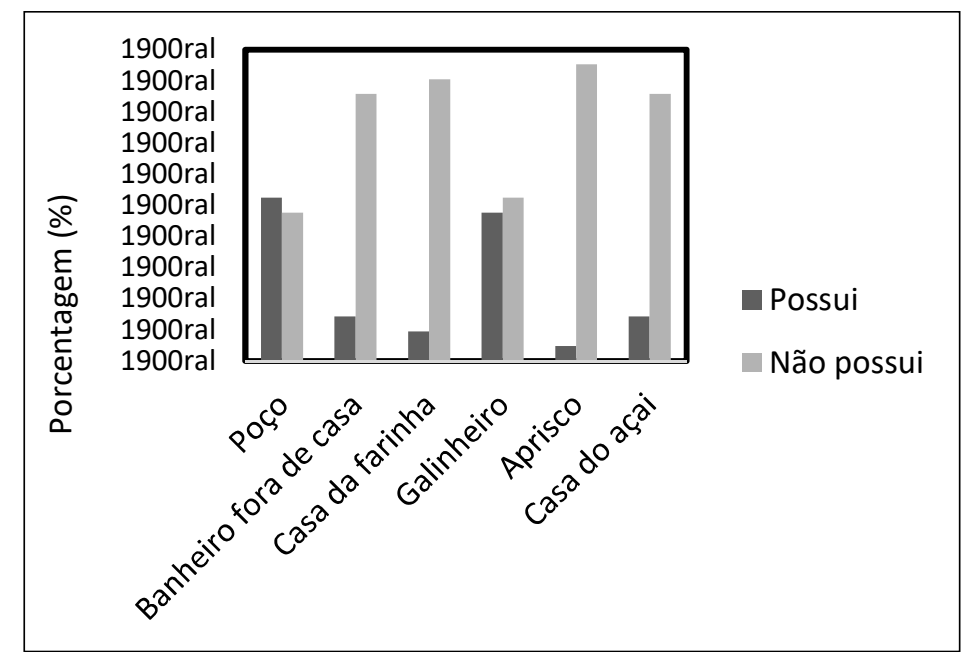

Figura 3: Benfeitorias existentes nas propriedades da comunidade Santa Luzia, Santarém (PA).

Considerando a presença e importância do igarapé, chamado de Babaçu, que corta a comunidade, levantou-se quantas propriedades têm a presença deste curso d'água, observando-se que $76,2 \%$ das propriedades são beneficiadas diretamente por ele. Além disso, os entrevistados foram questionados sobre de que forma usam a água do igarapé. Todos os entrevistados, mesmo aqueles que uso indiretamente este recurso, afirmaram usar para banho $(95,2 \%)$; lavar roupas $(61,9 \%)$, lavagem de roupas $(33,3 \%)$, beber $(28,6 \%)$, cozinhar $(28,6)$ e irrigação $(4,8 \%)$.

Os entrevistados que usam o igarapé para aproveitamento da água, bombeiam a água por meio de bomba sapo. Esta bomba puxa a água através de um sistema de tubo acoplado no olho d'água do igarapé, levando-a para uma caixa d'água da casa e a partir disso então ser distribuída para os pontos da residência, correspondendo assim a $28,6 \%$ das propriedades.

Para a irrigação (microaspersão) esta é realizada com a utilização de uma roda d'água, que segundo um entrevistado, é devidamente autorizada pelo órgão competente, visando a irrigação por microaspersão para a plantação de coco. Além da água do igarapé ser utilizada pelos comunitários para fins domésticos, ressalta-se que este recurso também é utilizado por visitantes, uma vez que na comunidade existem balneários.

\section{Percepção ambiental dos comunitários}

Os proprietários foram indagados sobre a mudança na vazão da água do igarapé. Segundo eles foram percebidas mudanças na vazão de água deste curso d'água. Em 33,3\% das dos casos verificou-se que há pelo menos nove anos têm sido observadas mudanças. Conforme se pode verificar na tabela 1 , tem-se algumas mudanças.

Tabela 1: Mudanças observadas na vazão do principal igarapé da comunidade de Santa Luzia, Santarém (PA).

\begin{tabular}{|l|c|}
\hline \multicolumn{1}{|c|}{ Mudança na vazão do igarapé } & Resposta dos entrevistados (\%) \\
\hline Coloração & 9,5 \\
\hline Profundidade e largura & 9,5 \\
\hline Profundidade, largura e coloração & 14,3 \\
\hline Profundidade e coloração & 9,5 \\
\hline Profundidade & 42,9 \\
\hline Nenhuma mudança & 14,3 \\
\hline
\end{tabular}


É importante citar que há relatos também de alterações na nascente do igarapé, conforme observado no relato a seguir: 'Em algumas partes, a coloração e profundidade. Na fonte tá igual, mesmo depois que os gados iam lá no período em que um vizinho criou'. Sobre a importância da mata ciliar, $81 \%$ dos entrevistados atribuíram importância máxima. Esta importância traz uma relação com a manutenção ao igarapé $(85,7 \%)$, qualidade do ar $(9,5 \%)$ e manutenção da vegetação, principalmente o açaí $(4,8 \%)$. Conforme relatos de algumas entrevistas para os respectivos fatores 'Devido à consciência de que não de mexer essa parte pois, se não poderemos ficar como São Paulo com falta d'água pois, fará falta. Por exemplo, matando o igarapé somos os principais afetados'.

Vale destacar falas que ressaltam a importância da mata ciliar para a conservação da biodiversidade, incluindo os micro-organismos: 'É a mata ciliar que protege o igarapé, os microrganismos que dependem desse sistema para sobreviver'; 'Porque conserva o igarapé também para o ar na comunidade fica mais puro do que na cidade'; 'Pelo açaí que estão nas matas e o cupuaçu para o pessoal da comunidade e por causa do igarapé'. Assim, os entrevistados demonstraram a importância do igarapé e da mata ciliar e de que maneira ambos estão interligados.

Para as propriedades que são contempladas com a passagem do igarapé, os entrevistados demonstraram suas percepções desvinculadas de aspectos legais. Isto é, para ele a ideia de preservação não está atrelada a metragem mínima prevista pela Lei no 12.651/2012. As propriedades com a presença do igarapé, a mata ciliar variou de 15 a 300 metros, com a grande maioria concentrada até 50 metros.

Nestas áreas são exploradas espécies vegetais em 14,3\% das propriedades avaliadas. As espécies mirapixuna, lacre, araracanga e ucúuba são as citadas por eles, além do açaizeiro. De acordo com os comunitários, a composição florística destas áreas é caracterizada pela presença das seguintes espécies: cedroraana, ipê, cumaru, piquiá, castanheira do Pará, andiroba, mirapixuna, lacre, pau Brasil, jarana e jacarandá.

Também se perguntou sobre a exploração de produtos florestais não madeireiros, ocorrendo em $81 \%$, sendo citados o açaí com maior destaque, seguido pelo óleo de andiroba, cumaru e palha. Dessa forma, observa-se baixo interesse por parte dos entrevistados em explorar as outras espécies para eles o grande atrativo é a população de açaí uma vez que este proporciona fonte de renda através de seus subprodutos representando $57,1 \%$ destinado à comercialização.

Ao serem questionados sobre o que entende por impacto ambiental, $81 \%$ associaram com destruição das matas, apontando como algo negativo. Algumas das respostas foram as seguintes: 'Causa dano ao meio ambiente. Em alguns casos pode ser reversível em outros não'; 'E o que a degradação traz para gente e que acarreta em coisas que deixamos de usufruir por exemplo animais que desaparecem, o aumento do calor'; 'Algo negativo para a natureza, tipo derrubar uma floresta na margem do igarapé'; 'Quando geralmente uma pessoa desmata um local, irá prejudicar como o que aconteceu com o projeto minha casa minha vida'. No que tange ao comprometimento do igarapé por diversas atividades antrópicas, o lançamento de lixo neste curso d'água $(85,7 \%)$ foi o mais citado (figura 4$)$. 


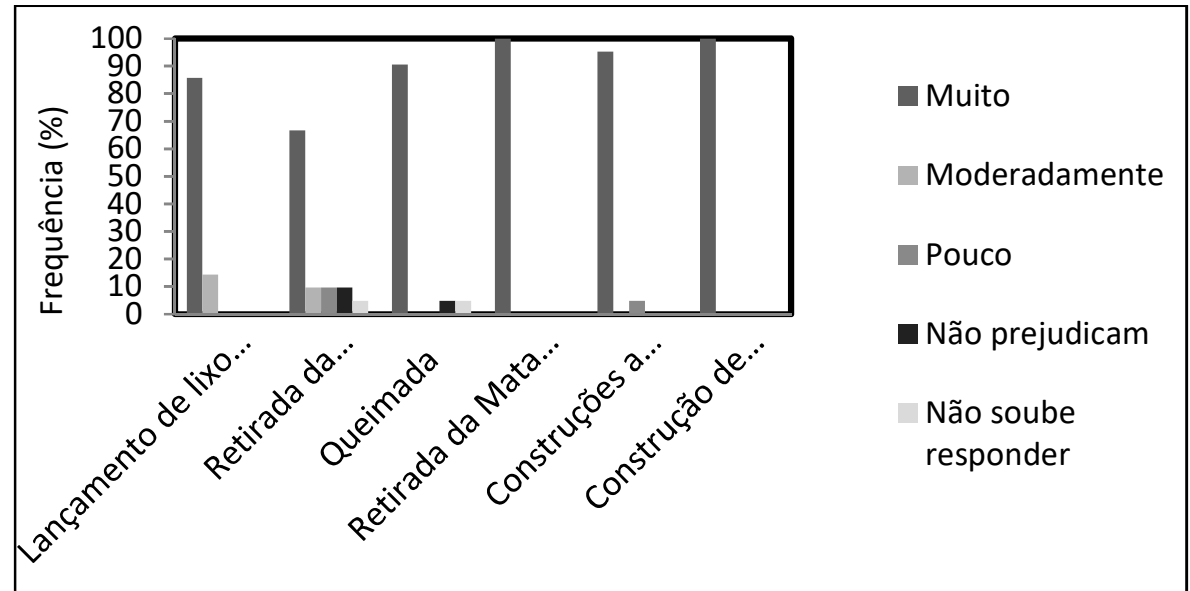

Figura 4: Atividades que prejudicam o igarapé conforme percepção dos moradores da comunidade de Santa Luzia, Santarém (PA).

Isto mostra a preocupação dos entrevistados com o descarte inadequado do lixo (resíduo sólido) no igarapé. Ressalta-se que na comunidade de Santa Luzia não há coleta de lixo, tendo os moradores que se deslocar até à margem da Rodovia Everaldo Martins para depositarem o resíduo produzido. No entanto, mesmo ocorrendo essa mobilização para a coleta foi constado uma pequena quantidade de focos de resíduos sólidos próximos ao igarapé, que em relatos de alguns entrevistados são ocasionados por visitantes principalmente no trecho do igarapé que eles denominam como comunitário.

Quando comparados os resultados dos questionários e observando a área de estudo, foi possível identificar que os resíduos gerados pelos moradores são na sua maioria lançados diretamente nas margens do rio. Os resíduos sólidos orgânico-inorgânicos continuamente jogados ao meio ambiente levam ao desequilíbrio de ecossistemas aquáticos, provocando diversos efeitos negativos. Em relação às queimadas, 90,5\% dos entrevistados responderam que prejudicam muito o igarapé. Mesmo tendo um resultado significativo quanto a consequência que essa ação pode vir a ocasionar, foi observado em campo pequenos focos de queimadas próximo ao igarapé.

Na visão dos entrevistados, a retirada da vegetação do estrato herbáceo (rasteiro) prejudica muito $(66,7 \%)$, bem como a supressão de toda mata ciliar (100\%) prejudica o equilíbrio ambiental. A retirada de parte da vegetação nativa (herbácea ou arbórea) do igarapé resulta em um desequilíbrio, com perda na biodiversidade, além de comprometer o microclima e a própria existência do habitat aquático. Lima et al. (2013) ressalta que

A destruição da vegetação ciliar ao longo dos cursos d'água é a porta de entrada para diferentes elementos capazes de alterar as características dos ambientes aquáticos (sedimentos, areia, efluentes domésticos, resíduos, contaminantes, etc.), inviabilizando o uso deste recurso tão valioso, a água, além de maximizar os impactos ligados ao uso e ocupação desordenados das áreas urbanas como enchentes, alagamentos, desmoronamentos e proliferação de pragas e doenças.

Em relação à atividade construção de banheiro, pode-se observar que, em conversas com os comunitários, a preocupação para que essa atividade não ocorra é grande, demonstrada pela presença de propriedades fossas ecológicas, executada em parceria com a Empresa de Assistência Técnica e Extensão Rural do Pará. Também avaliaram as construções a margem do igarapé $(95,2 \%)$ consideraram prejudicial ao equilíbrio ambiental. 
Os entrevistados foram questionados sobre a existência de atividade realizada na comunidade que possa vim a prejudicar a mata ciliar onde $90,5 \%$ consideraram que sim. Para eles as construções (piscinas, tablados e na margem do igarapé) são as principais ameaças. Alguns dos entrevistados enfatizaram que: 'Construções das piscinas, balneários estão causando a baixa do nível do igarapé. Devido à retirada da mata ciliar'; 'As construções a margem do igarapé principalmente pelas pessoas de fora. Pois, fazem piscinas, construções as margens. Retirando toda a mata ciliar'; 'Muitos banhistas que compraram terreno com igarapé. Acabam retirando a mata ciliar para construção de tablado'; 'As construções a margem do igarapé como os tablados. A pessoa sabe que não é para fazer mesmo assim faz'; 'As pessoas que vem toma banho e jogam lixo. Além das pessoas que compraram lotes e querem construir a margem do igarapé'; 'O lixo que o pessoal de fora joga no igarapé. E as construções a margem do igarapé feito pelo pessoal de fora'.

Sobre a contribuição deles para a preservação da mata ciliar foi dito que: 'Procura sensibilizar as pessoas sobre o uso dos recursos naturais que podem vim esgotar'; 'Através da sensibilização e não desmatando a mata ciliar'; 'Minha família fazem replantio porque sabem a importância já moraram na comunidade São Brás sentem a diferença'; 'Procuro um órgão competente para auxiliar como por exemplo a Secretaria Municipal de Meio Ambiente-SEMMA'; 'Procura conversar com as pessoas que fazem isso por exemplo no roçado para fazerem a limpeza no fim da tarde como o uso do fogo para evitar acidente'; 'Procuro conversar com as pessoas que fazem esses banhos irregulares no caso as piscinas'.

\section{DISCUSSÃO}

Acredita-se que o tempo de moradia em uma dada comunidade rural possa refletir na percepção ambiental do indivíduo sobre o ambiente que Ihe cerca. Isto vai ao encontro do que aponta Ribeiro et al. (2012), quando considerara que a idade e o tempo de residência em um dado local apresentam alguma associação capaz de influenciar na percepção ambiental.

Os comunitários de Santa Luiza mesmo não havendo escola na comunidade, os entrevistados possuem nível de escolaridade favorável a adequadas percepções ambientais. No dia a dia, necessitam se deslocar até a comunidade mais próxima no caso São Brás ou à sede da cidade de Santarém. Pode-se considerar que, por se tratar de uma comunidade próxima à cidade, o acesso à escolaridade não é considerado uma barreira para eles.

Ao verifica-se as mudanças relacionadas ao igarapé podem ter sido ocasionadas pela supressão da mata ciliar, em geral visando área para a construção de balneários, sendo que na comunidade, segundo relatos, chegam a 10 balneários espalhados na comunidade. Tal prática vem contribuindo para a ocorrência da mudança no fluxo do igarapé, no entanto, os comunitários locais buscam conversar com essas pessoas, na tentativa de promover um diálogo para que eles não realizem esse tipo de ação. Segundo relatos, isto fere o estatuto da associação da comunidade. Esses tipos de relatos chamam atenção pois, a degradação dos recursos naturais está diretamente ligada a ações antrópicas que necessitam cada vez mais serem freadas e com isso continuasse usufruindo dos bens e serviços que tal ecossistema aquático proporciona.

Souza et al. (2009) identificou a presença de casas de veraneio com estruturas de pisos de cimento 
nas margens do igarapé da comunidade de São Braz, localizada no mesmo PAE e próximo da comunidade de Santa Luzia. Isto mostra a falta de respeito ao ambiente e as leis ambientais brasileiras. Já no aspecto mudança na coloração na água do igarapé se deve ao escoamento superficial, que segundo Pizzato et al. (2009), "é constituído pela água que escoa sobre o solo, fluindo para locais de altitudes inferiores até então atingir um corpo de água como rio, lago ou oceano". Além disso, de acordo com Esteves (2011), no período das chuvas ocorrem profundas alterações no corpo d'água (volume, intensidade e direção de correntes, turbidez, regimes de gases, disponibilidade e diversidade de alimento, entre outros), como também na comunidade zooplanctônica.

Os comunitários lembram que ainda podem desfrutar de um ambiente equilibrado, principalmente em comparação a outras comunidades do PAE Eixo Forte, sendo o igarapé do Babaçu motivo desta sensação. Junior et al. (2013) identificou boas ideias de preservação das matas ciliares, em função dos benefícios que este tipo de vegetação traz: preservação da natureza; qualidade da água; e melhoria do clima.

No que tange a parte ambiental observa-se que por mais que os comunitários façam sua parte é necessário que os visitantes tenham percepção ambiental compatível com a conservação colaborando dessa maneira para a manutenção desse ecossistema, como destaca Coelho (2012), o qual constatou que, ao serem questionados sobre o destino do lixo, os entrevistados alvo de seu estudo responderam que colocam o lixo na lixeira (83\%).

Os entrevistados atuam de alguma maneira para a prática da preservação das matas ciliares, no entanto, no atual contexto da comunidade eles fazem a conservação desse recurso uma vez que exploram o açaí, cupuaçu e taperebá. Os relatos apontam para a motivação e vontade em manter a mata ciliar, seja pelo trabalho de sensibilização destes com outras pessoas, principalmente visitantes, seja por meio da importância atribuída às matas ciliares por cada um dos sujeitos entrevistados.

Os comunitários de Santa Luzia foram questionados sobre a participação em palestras, cursos, oficinas, cujo o foco fossem as questões ambientais. Muitos informaram já ter participado, principalmente em parceria com a EMATER-Pará. Os principais temas citados foram: novo código florestal, legislação ambiental, manejo de açaizal nativo, ecoturismo e zoneamento ecológico. Tais temas são considerados pertinentes logo, despertando nos mesmos a responsabilidade ambiental em relação ao meio que estão inseridos.

\section{CONCLUSÕES}

O estudo realizado na comunidade de Santa Luzia, Projeto de Assentamento Agroextrativista Eixo Forte, Santarém, Pará, mostrou que os moradores possuem conhecimentos sobre os recursos naturais existentes na comunidade, com destaque ao igarapé e sua mata ciliar, sendo estes considerados com importante valor ambiental, tendo eles a sensibilização pela harmonia no equilíbrio ambiental. Há a sensibilização dos visitantes, principalmente os que têm balneários, para as questões ambientais. No entanto, ainda ocorrem descartes irregulares de resíduos às margens do igarapé da comunidade. 
O conhecimento sobre a legislação ambiental envolvendo a mata ciliar é superficial, havendo ainda muitas limitações. Assim, surge a necessidade de ampliar as ações extensionistas voltadas para as questões de legislação ambiental, por meio de cursos, oficinas e/ou palestras sobre aspectos legislacionais e de educação ambiental para a realidade local.

\section{REFERÊNCIAS}

ATTANASIO, C. M.; RODRIGUES, R. R.; GANDOLFI, S.; NAVE, A. G.. Adequação ambiental de propriedades rurais recuperação de áreas degradadas restauração de matas ciliares. Piracicaba: USP, 2006.

\section{BARBAULT, R.. Ecologia Geral: Estrutura e Funcionamento} da Biosfera. Rio de Janeiro: Vozes, 2011.

BRASIL. Lei n.12651 de $\mathbf{2 5}$ de maio de 2012. Dispõe sobre a proteção da vegetação nativa; altera as Leis n. 6938, de 31 de agosto de 1981, 9393, de 19 de dezembro de 1996, e 11428, de 22 de dezembro de 2006; revoga as Leis n.4771, de 15 de setembro de 1965, e 7754, de 14 de abril de 1989, e a Medida Provisória n.2166, de 24 de agosto de 2001; e dá outras providências. Brasília: DOU, 2012.

BRASIL. Lei $\mathbf{n . 6 9 3 8}$ de 31 de agosto de 1981. Dispõe sobre a Política Nacional de Meio Ambiente; seus fins e mecanismos de formulação e aplicação e dá outras providências. Brasília: DOU, 1981.

COELHO, A. A.. Percepção ambiental dos moradores ribeirinhos do médio Itapecuru em Rosário-MA como subsídio a uma proposta de educação ambiental. Revista Brasileira de Educação Ambiental, Rio Grande, v.7, n.2, p.37-43, 2012.

ESTEVES, F. A.. Fundamentos de Liminologia. 3 ed. Rio de Janeiro: Interciência, 2011.

FENDEL, K. L.. Recuperação de Mata Ciliar com Sistema Agroflorestal, Itajaí - SC. Monografia (Graduação em Ciências Biológicas) - Universidade do Vale do Itajaí, Itajaí, 2007.

GALAVOTTI, G. D.. Diagnóstico do uso do solo e cobertura vegetal $\mathrm{mm}$ áreas de preservação permanente ao longo dos cursos d'água na APA Sul RMBH. Monografia (PósGraduação em Geoprocessamento) - Universidade Federal de Minas Gerais, Belo Horizonte, 2005.

JUNIOR, A. C. P.; CARVALHO, S. L.; LIMA, E. A. C. F.. Percepção ambiental de produtores rurais e condições ambientais de algumas propriedades agrícolas da região de Bauru - SP. In: FÓRUM AMBIENTAL DA ATLAS PAULISTA, 9. Anais. São Paulo: ANAP, 2013.

LIMA, J. A.; ANDRADE, N. L. R.; OROZCO, M. M. D.; BEZERRA, R. R.; RUDKE, A. P.. Aplicação do método verah para diagnóstico ambiental da cabeceira de drenagem do igarapé Piraíba no município de Ji-Paraná-RO. In: SIMPÓSIO BASILEIRO DE RECURSOS HÍDRICOS, 20. Anais. Bento Gonçalves: ABRH, 2013.

MELLAZO, G. C.. A percepção ambiental e educação ambiental: uma reflexão sobre as relações interpessoais e ambientais no espaço urbano. Olhares \& Trilhas,
Uberlândia, v.6, n.6, p.45-51, 2005.

MORO, J. C.; COSTA, E. T. V.; MILANESES, S.; MORO, R. S.. Comparação da cobertura vegetal nas áreas de preservação permanente na represa de Alagados (PR), de 1980 a 2001. Publicatio UEPG: Biological and Health Sciences, v.11, n.2, p.13-20, 2005.

NASCIMENTO, D. A. M.; CIHODA, J. M. C.; SILVA, L. M. S.; SOUZA, R. O.. Avaliação da percepção ambiental de moradores da malha urbana de Presidente Prudente. Colloquium Exactarum, Presidente Prudente, v.3, n.1, p.2833, 2011.

OLIVEIRA, L. C.; PEREIRA, R.; VIEIRA, J. R. G.. Análise da degradação ambiental da mata ciliar em um trecho do Rio Maxaranguape - RN: uma contribuição à gestão dos recursos hídricos do Rio Grande do Norte - Brasil. HOLOS, v.27, n.5, p.49-66, 2011.

OLIVEIRA, T. L. F.; VARGAS, I. A.. Vivências integradas à natureza: por uma educação ambiental que estimule os sentidos. Revista Eletrônica do Mestrado em Educação Ambiental, Rio Grande, v.22, p.309-322, 2009.

PIZZATO, L.; PIZZATO, R.. Dicionário socioambiental brasileiro. 22 ed. Curitiba: TEd, 2009.

REVELINI, E. V. P.. Avaliação do programa mata ciliar na microbacia Ribeirão Laranja Doce - município de Borrazópolis/PR: a percepção dos agricultores. Monografia (Pós-Graduação em Administração Pública) - Universidade Estadual de Londrina, Londrina, 2011.

RIBEIRO, A. R.; CELERE, B. S.; MELHADO, L. Z.; GUIMARÃES, P. S.. Percepção ambiental dos moradores no bairro Jardim Tangará. In: CONGRESSO DE MÉDIO AMBIENTE, 7. Anais. La Plata: UNLP, 2012.

SÁNCHEZ, L. E.. Avaliação de Impacto Ambiental: Conceitos e Métodos. São Paulo: Oficina de Textos, 2006.

SCARDUA, V. M.. Crianças e meio ambiente: a importância da educação ambiental na educação infantil. FACEVV, Vila Velha, n.3, p.57-64, 2009.

SHORUPA, L. A.. Áreas de Preservação Permanente e Desenvolvimento Sustentável. Jaguariúna: Embrapa, 2003.

SILVA, M. M. P.; LEITE, V. D.. Estratégias para realização de educação ambiental em escolas do ensino fundamental. Revista Eletrônica do Mestrado em Educação Ambiental, Rio Grande, v.20, p.372-392, 2008.

SOARES, N. B.. Educação ambiental no meio rural: estudo das práticas ambientais da escola Dario Vitorino Chagas, Comunidade rural do umbu - Cacequi/RS. Dissertação 
(Mestrado em Educação Ambiental) - Universidade Federal de Santa Maria, Santa Maria, 2007.

SOUZA, D. R.; CABRAL, A. S.; NOBRE, D.; LOBATO, H.; GOCH, Y.; PELEJA, R. J.; CABRAL, W. S.. Diagnóstico e físico químico dos igarapés no trecho de Santarém a vila balneária de Alter do Chão - PA. Em foco, Santarém, v.6, n.11, p.7585, 2009.

TERAMUSSI, T.. Percepção ambiental de estudantes sobre o parque ecológico do Tietê, São Paulo - SP. Dissertação (Mestrado em Ciência Ambiental área de concentração Ciência Ambiental) - Universidade de São Paulo, São Paulo, 2008.

UCHÔA, P.W. S.. Estudo de variações termo-higrométricas de cidade equatorial devido ao processo de urbanização: 0 caso de Santarém - PA. Dissertação (Mestre em Recursos Naturais da Amazônia) - Universidade Federal do Oeste do Pará, Santarém, 2011.

A CBPC - Companhia Brasileira de Produção Científica (CNPJ: 11.221.422/0001-03) detém os direitos materiais desta publicação. Os direitos referem-se à publicação do trabalho em qualquer parte do mundo, incluindo os direitos às renovações, expansões e disseminações da contribuição, bem como outros direitos subsidiários. Todos os trabalhos publicados eletronicamente poderão posteriormente ser publicados em coletâneas impressas sob coordenação da Sustenere Publishing, da Companhia Brasileira de Produção Científica e seus parceiros autorizados. Os (as) autores (as) preservam os direitos autorais, mas não têm permissão para a publicação da contribuição em outro meio, impresso ou digital, em português ou em tradução. 